\title{
Testing the Role of Habitat Isolation among Ecologically Divergent Gall Wasp Populations
}

\author{
Scott P. Egan, ${ }^{1,2}$ Glen R. Hood, ${ }^{1}$ and James R. Ott ${ }^{3}$ \\ ${ }^{1}$ Department of Biological Sciences, University of Notre Dame, Notre Dame, IN 46556, USA \\ ${ }^{2}$ Advanced Diagnostics and Therapeutics, University of Notre Dame, Notre Dame, IN 46556, USA \\ ${ }^{3}$ Population and Conservation Biology Program, Department of Biology, Texas State University-San Marcos, \\ San Marcos, TX 78666, USA \\ Correspondence should be addressed to Scott P. Egan, scott.p.egan@nd.edu
}

Received 17 October 2011; Accepted 9 January 2012

Academic Editor: Marianne Elias

Copyright ( $) 2012$ Scott P. Egan et al. This is an open access article distributed under the Creative Commons Attribution License, which permits unrestricted use, distribution, and reproduction in any medium, provided the original work is properly cited.

Habitat isolation occurs when habitat preferences lower the probability of mating between individuals associated with differing habitats. While a potential barrier to gene flow during ecological speciation, the effect of habitat isolation on reproductive isolation has rarely been directly tested. Herein, we first estimated habitat preference for each of six populations of the gall wasp Belonocnema treatae inhabiting either Quercus virginiana or Q. geminata. We then estimated the importance of habitat isolation in generating reproductive isolation between $B$. treatae populations that were host specific to either Q. virginiana or Q. geminata by measuring mate preference in the presence and absence of the respective host plants. All populations exhibited host preference for their native plant, and assortative mating increased significantly in the presence of the respective host plants. This host-plant-mediated assortative mating demonstrates that habitat isolation likely plays an important role in promoting reproductive isolation among populations of this host-specific gall former.

\section{Introduction}

Ecological speciation describes the process by which reproductive isolation evolves as a consequence of divergent natural selection between environments $[1,2]$. Studies of ecological speciation seek to associate the origin of specific reproductive isolating barriers that reduce gene flow with sources of divergent selection [3]. Throughout the modern synthesis, biologists described a central role of ecological adaptation in the speciation process [4-6]; however, it was not until a recent renaissance of empirical study that specific ecological barriers have been experimentally shown to contribute to reproductive isolation. In strong support of the role of ecology in speciation, a comparative study across many plant and animal taxa provided evidence that ecological adaptation generally contributes to the evolution of reproductive isolation [7].

Recent studies of the role of ecology in speciation have documented a central role of divergent natural selection in the speciation process among a diverse set of taxa (e.g.,
Rhagoletis fruit flies [8], Littorina snails [9], Neochlamisus leaf beetles [10], Gasterosteus aculeatus sticklebacks [11], Gambusia fishes [12], Timema walking sticks [13], Mimulus monkeyflowers [14], and cynipid gall wasps [15]). Moreover, these studies have documented that a diversity of both prezygotic and postzygotic reproductive barriers can arise as a result of divergent ecological adaptation $[3,16]$, including temporal isolation [17], sexual isolation [18], cryptic isolation [19], and extrinsic (ecological) postzygotic isolation $[20,21]$.

The study of ecological speciation has been especially informed by studies of herbivorous insects $[22,23]$. The intimate interactions between herbivorous insects and their host plants suggest a strong role for divergent natural selection in promoting diversification. Herbivorous insects tend to be highly specialized in their use of host plant taxa [24], and specialized insect herbivores can exhibit pronounced geographic variation in, and rapid evolution of, host plant preference and performance traits (e.g., $[25,26])$. The increased rates of speciation associated with herbivory among insects 
TABLE 1: Locations and host plant associations of the six B. treatae populations from central Florida used in the present study.

\begin{tabular}{llll}
\hline Population & $\begin{array}{c}\text { Host } \\
\text { association }\end{array}$ & Latitude & Longitude \\
\hline Near Avon Park (AP) & Q. geminata & $27^{\circ} 36^{\prime} 00^{\prime \prime} \mathrm{N}$ & $81^{\circ} 30^{\prime} 42^{\prime \prime} \mathrm{W}$ \\
Scrub field (S) & Q. geminata & $27^{\circ} 30^{\prime} 48^{\prime \prime} \mathrm{N}$ & $81^{\circ} 20^{\prime} 16^{\prime \prime} \mathrm{W}$ \\
Archbold Biological Station (ABS)* & Q. geminata & $27^{\circ} 10^{\prime} 57^{\prime \prime} \mathrm{N}$ & $81^{\circ} 21^{\prime} 08^{\prime \prime} \mathrm{W}$ \\
Near Hickory Hammock Natural Area (HH)* & Q. virginiana & $27^{\circ} 24^{\prime} 09^{\prime \prime} \mathrm{N}$ & $81^{\circ} 06^{\prime} 42^{\prime \prime} \mathrm{W}$ \\
Gatorama (GR) & Q. virginiana & $26^{\circ} 55^{\prime} 30^{\prime \prime} \mathrm{N}$ & $81^{\circ} 18^{\prime} 44^{\prime \prime} \mathrm{W}$ \\
Near Koreshan State Park (KSP) & Q. virginiana & $26^{\circ} 26^{\prime} 04^{\prime \prime} \mathrm{N}$ & $81^{\circ} 48^{\prime} 56^{\prime \prime} \mathrm{W}$ \\
\hline
\end{tabular}

${ }^{*}$ Denotes populations used in the mate preference tests.

provides evidence that host plant ecology may generally contribute to the speciation process $[27,28]$.

Walsh [29] was one of the first to associate phenotypic variation among insects with the host plants upon which they were found and Bush [30] was one of the first to argue for a direct role of host-plant-associated selection in the genesis of new insect species. Continued work has since highlighted the role of divergent selection due to host plant use among taxa where gene flow is possible (e.g., $[8,10$, $13,17,31,32])$. A critical barrier to gene flow among specialist herbivore insect taxa is "habitat isolation" $[8,16$, 30]. Habitat isolation for host-specific phytophagous insect species describes the process by which the differing habitat preferences of insect populations associated with alternative host plants reduces the frequency of encounters and thus the likelihood of mating between individuals from the differing host-associated populations. For example, Nosil et al. [33] examined 27 populations of Timema cristinae walking sticks feeding on Ceanothus or Adenostoma host plants. Populations of walking sticks on different host plants expressed stronger divergence in host plant preference than populations on the same host plant. These differences likely result in reduced encounters among individuals preferring different hosts. Similar inferences regarding the role of host plant preference in speciation have been made for leaf beetles [10], pea aphids [32], ladybird beetles [34], Rhagoletis fruit flies [8, 35], and Eurosta galling flies [36].

However, rarely has the effect of observed differences in host plant preference on reproductive isolation been tested directly [23]. Field studies of the apple and hawthorn host races of Rhagoletis pomonella found evidence that host plant preference could generate habitat isolation [8]. Here, the apple and hawthorn host races returned to their natal plant species when released in the presence of both apple and hawthorn trees. Because these host races mate on their host plant it is likely that host preference translates into hostassociated assortative mating that restricts gene flow between the ecologically divergent populations. In a direct laboratorybased test of habitat isolation, Funk [10] performed mating assays among ecologically divergent host forms of the leaf beetle Neochlamisus bebbianae. To isolate the role of the host plant on overall sexual isolation, the host plant of each individual was included in half of the mating assays. Results from Funk [10] were mixed, with one of the four different host comparisons of $N$. bebbianae populations exhibiting a significant increase in assortative mating due to host plant presence.

In the present study, we use a combination of habitat preference and mate preference assays among ecologically divergent populations of the gall wasp Belonocnema treatae (Hymenoptera: Cynipidae) to test for (a) variation among host-associated populations in habitat (i.e., host plant) preference and (b) an explicit role for habitat isolation in overall reproductive isolation. We test these hypotheses using populations of $B$. treatae that inhabit two sister species of live oak, Quercus virginiana and Q. geminata, which geographically overlap in the southeastern United States. The habitat of each oak differs slightly, with Q. virginiana occurring in moister, more nutrient rich, and higher $\mathrm{pH}$ sites than Q. geminata [37], and the oaks themselves differ in leaf morphology and flowering times [38]. Populations of $B$. treatae that inhabit these oak species exhibit significant differences in root gall structure and adult body size that are associated with host use, and gall wasp populations exhibit host-associated assortative mating [15].

\section{Methods}

2.1. Study System and Sampling. Belonocnema treatae is a host-specific gall former [39] that exhibits regional specificity (Ott and Egan, personal observation) on species of live oak, Quercus, within the Virentes series of the genus [40]. Belonocnema treatae exhibits a heterogonous life cycle with temporally segregated sexual and asexual generations [39]. The asexual generation develops within single-chambered, spherical galls on the undersides of leaves during the summer and fall and emerges in the winter. The sexual generation develops within multichambered galls on the root tissue, and males and females emerge during the spring. We collected root galls containing the sexual generation from six allopatric populations in central Florida in April 2010 (three Q. geminata and three $Q$. virginiana populations; see Table 1 for location information). Galls were husbanded under common laboratory conditions (12:12 light : dark, $\left.23^{\circ} \mathrm{C}\right)$, and upon emergence adults were sorted by sex and population for host preference and mating assays, which took place within 48 hours of emergence.

2.2. Host Preference Assays. Trials took place within $25 \times$ $8 \mathrm{~cm}$ clear-plastic cups stocked with a cutting of each host 


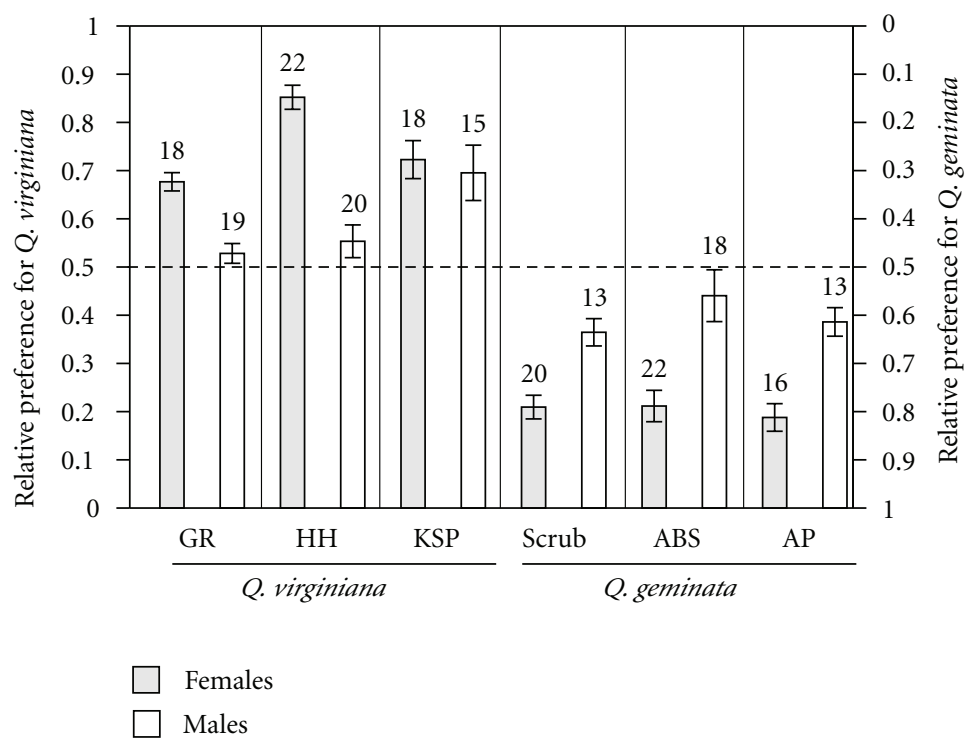

Figure 1: Host preference of individual B. treatae gall wasps expressed for each of three Q. virginiana and three Q. geminata host-associated populations during choice tests that paired each wasp's native/natal host with the alternative oak species. Illustrated is the mean $( \pm$ SE) of the proportion of time spent on the native host plant by each sex within each population. The dashed line highlights no preference (defined as $50 \%$ of time spent on each host). Note each population differed significantly from $50 \%(P<0.0001)$. Numbers above the SEs are the number of replicates. Note the reversed left and right $y$-axis.

plant (Q. virginiana and Q. geminata). A single B. treatae was aspirated into each cup and then observed at five-minute intervals for one hour for a total of 12 observations. At each time point, we recorded the location (on Q. virginiana, on $Q$. geminata, or on the cup) of each individual. Both sexes were tested. Host preference was calculated for each individual as the relative time spent on one host plant species divided by the total time spent on both host plants during the trials (e.g., individual preference for Q. virginiana $=$ (number of observations on $Q$. virginiana)/(number of observations on Q. virginiana + number of observations on Q. geminata)). We performed a total of 214 preference assays distributed across the six B. treatae populations (see Figure 1 for sample sizes per population).

2.3. Assays of Sexual Isolation with an Explicit Test of Habitat Isolation. No-choice mating trials were conducted to test for assortative mating as a function of population of origin between one population (ABS-Archbold Biological Station, FL) of $B$. treatae reared from galls that developed on Q. geminata and one population ( $\mathrm{HH}$-near Hickory Hammock State Natural Area, FL) reared from galls on $Q$. virginiana $(N=291$ total; see Figure 2 for sample sizes per treatment). Trials again took place within $25 \times 8 \mathrm{~cm}$ clear-plastic cups. In half of the trials we placed a small, defoliated, dried twig for the wasps to walk on as a control. Alternatively, in half the trials a small leaf-bearing section of stem of the species of oak representing each individual's host plant was added. One male and one female were then aspirated into each cup (replicate). Each pair was observed at

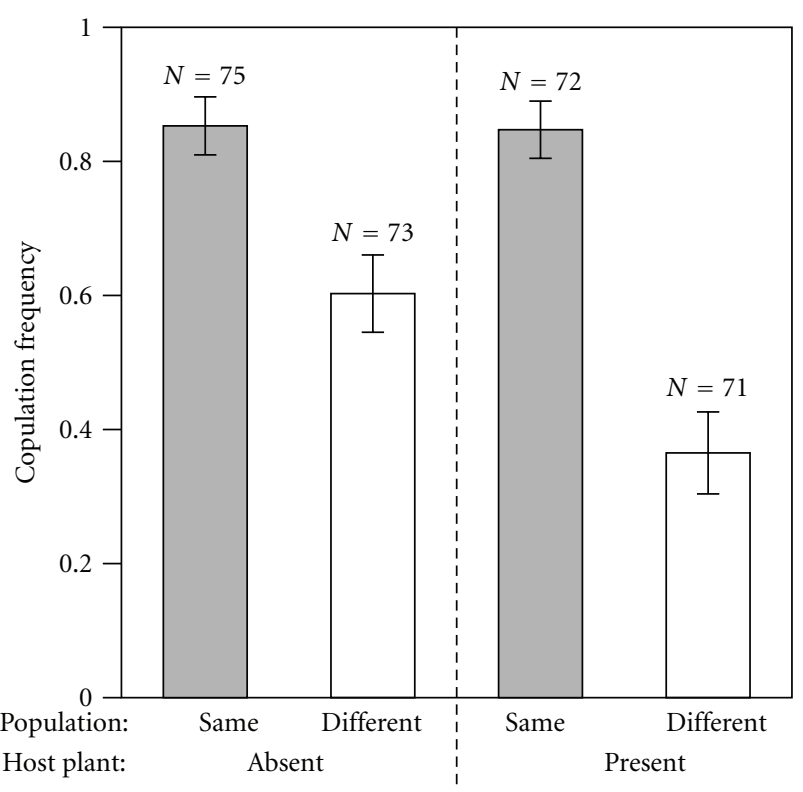

Figure 2: Mean $( \pm \mathrm{SE})$ of copulation frequency among $B$. treatae individuals from their own host-associated population or the alternative host-plant-associated population when host plants were absent or present. Sexual isolation is indicated by a difference between copulation frequency when paired with an individual from the "same" host plant population versus a "different" host plant population. The additional effect of habitat isolation is indicated by a shift in the magnitude of the difference between same and different host pairings when the host plant is present during the mating assay. Numbers above the SEs are the number of replicates. 
five-minute intervals for one hour for a total of 12 observations. At each survey we recorded each individual's location (on Q. virginiana, on Q. geminata, or test arena) and whether the pair was copulating. Copulations were defined as males having mounted the female with abdomens in contact. An additional estimate of host plant preference was calculated during these mating trials based on the proportion of time ( $n / 12$ observation periods) that wasps of each sex were observed on each host plant. Estimates were then converted to a relative value of host preference as previously described. For interpopulation pairings, the average host preference of males and females was compared to the probability of a successful hybrid mating (i.e., copulation).

2.4. Statistical Analyses. To test for differences in host plant preferences of individual wasps between the sexes, among populations, and their interaction, we conducted an ANOVA on individual relative preference for $Q$. virginiana (1preference for Q. geminata) followed by Tukey's HSD test to compare means among populations. Population was treated as a random effect; sex was treated as a fixed effect. A similar analysis of host preference expressed by individual wasps from the two population sources when the sexes were paired for the mating assays was also performed. We also compared each population's relative preference for its native host to a value of 0.5 by means of a $t$-test. The value 0.5 indicates equal time spent on each of the two host plants and characterizes "no preference."

To test for assortative mating, we used logistic regression to examine the effects of male host plant, female host plant, the presence/absence of the host plant, and their interactions on copulation frequency in the mating assays. The twoway interaction term, female host plant $\times$ male host plant, tests for overall assortative mating whereas the three-way interaction term, female host plant $\times$ male host plant $\times$ host plant present/absent, tests the effect of habitat preference on assortative mating. To examine the role of habitat isolation on sexual isolation further, we compared the host preference expressed by the male and female in each interpopulation mating assay when host plants were present between those assays that resulted in a "hybrid" copulation and those that did not by means of a standard $t$-test.

\section{Results}

3.1. Habitat Plant Preference. Geographic variation in relative host plant preference among the six B. treatae populations is evidenced by the significant population term in the ANOVA of host preference assays (Table 2). The difference in preferences among the populations is clearly associated with the host plant from which the $B$. treatae populations were collected (Figure 1). Each population preferred its native host, as shown by the highly significant difference between relative preference for native host and the no-choice expectation of equal time ( $t$-test of population mean versus 0.5 : KSP $t_{\mathrm{df}=32}=6.31, \mathrm{HH} t_{\mathrm{df}=41}=6.76, \mathrm{GR} t_{\mathrm{df}=36}=5.42$, AP $t_{\mathrm{df}=29}=8.11$, ABS $t_{\mathrm{df}=38}=5.45, \mathrm{~S} t_{\mathrm{df}=33}=10.11$; $P<0.0001$ for all comparisons). There was also significant variation among $Q$. virginiana associated populations in the
TABLE 2: ANOVA: sources of variation in relative host plant preference of individual $B$. treatae assessed from no-choice preference assays.

\begin{tabular}{lcccc}
\hline Source & df & SS & $F$ & $P$ \\
\hline Population & 5 & 2124.1 & 29.88 & $<0.0001$ \\
Sex & 1 & 10.1 & 0.71 & 0.4009 \\
Population $\times$ sex & 5 & 585.7 & 8.24 & $<0.0001$ \\
Error & 203 & 5803.1 & & \\
\hline
\end{tabular}

degree of preference for the native host plant. The KSP and $\mathrm{HH}$ populations exhibited stronger preferences than the GR population as shown by Tukey's HSD test following the ANOVA $(\mathrm{KSP}=0.71 \pm 0.02 \mathrm{SE}, \mathrm{HH}=0.70 \pm 0.02 \mathrm{SE}, \mathrm{GR}=$ $0.60 \pm 0.02 \mathrm{SE}$; Tukey's HSD test: $[\mathrm{KSP}=\mathrm{HH}]>\mathrm{GR}, P<0.05$; Figure 1). The three populations of $B$. treatae associated with Q. geminata did not differ in their degree of native host preference $(\mathrm{ABS}=0.33 \pm 0.02 \mathrm{SE}, \mathrm{S}=0.28 \pm 0.03 \mathrm{SE}, \mathrm{AP}$ $=0.29 \pm 0.03 \mathrm{SE}$; Tukey's HSD test: $\mathrm{ABS}=\mathrm{S}=\mathrm{AP}], P \gg$ 0.05; Figure 1). Females consistently expressed stronger host preference than did males for their native host plant across all six populations (Figure 1). The significant population $\times$ sex interaction term in the ANOVA (Table 2) demonstrates that the degree of difference between males and females in host preference varied by population. For example, males and females from KSP preferred their native host $Q$. virginiana similarly, but males and females from $\mathrm{HH}$ varied by over $30 \%$, with females expressing strong host preference for $Q$. virginiana and males spending a similar amount of time on each host plant (Figure 1).

3.2. Host Plant Effects on Mating Preference. Patterns of $B$. treatae copulation frequency (number of copulations/ number of mating trials) revealed strong evidence of hostassociated sexual isolation between individual gall wasps from the $\mathrm{HH}$ Q. virginiana and the $\mathrm{ABS} Q$. geminata source populations. Importantly for the hypothesis that habitat isolation drives reproductive isolation, $B$. treatae gall wasps were more likely to copulate when paired with individuals from the same host plant than from the alternative host plant as shown by the significant interaction term, female host $\times$ male host (Table 3, Figure 2). Moreover, the magnitude of sexual isolation significantly increased in the presence of the host plant (three-way interaction: female host $\times$ male host $\times$ host plant; Table 2 ). This result is explained in part by the $47 \%$ decrease in the frequency of between-host matings when host plants were present during the mating assays (Figure 2). This result is likely due to the intrinsic effect of habitat isolation arising from host preference that is effective even within the confines of the small enclosures used for the mating assays.

The average host preference expressed by paired male and female $B$. treatae during mating trials was similar to that revealed by the testing of individuals shown in Figure 1. However, if a mating did occur between $B$. treatae from different host plants, the average host preference expressed by a pair of individuals was associated with the degree of sexual isolation among them. Interestingly, this appeared to 

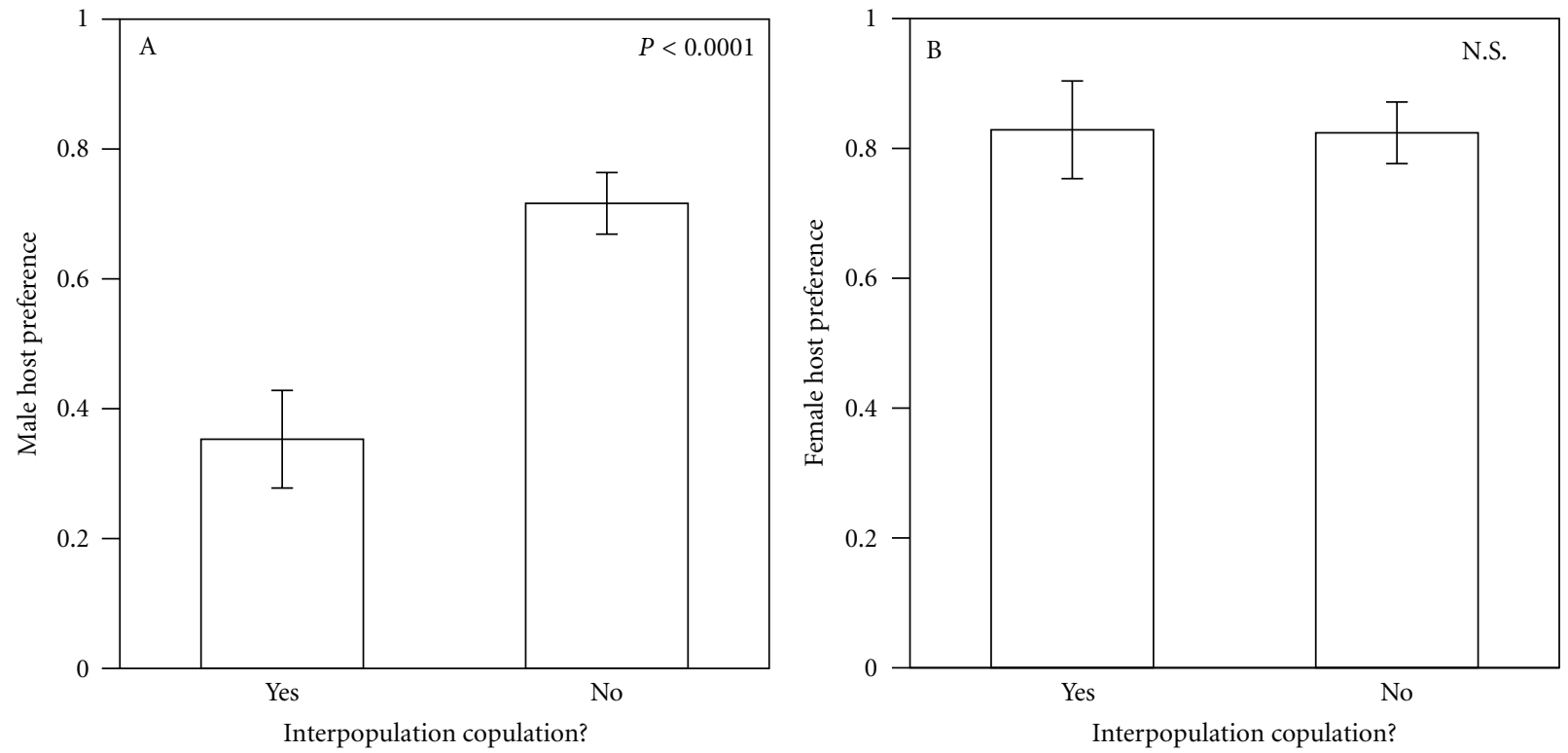

FIGURE 3: Mean $( \pm$ SE) of relative host preference expressed by individual (A) males and (B) females in the interpopulation (Q. geminata $\times$ Q. virginiana) mating trials as a function of copulation success. The greater observed host preference of males in those mating trials that did not result in a copulation further support the role of habitat isolation as an important premating reproductive barrier among gall wasp populations.

TABLE 3: Logistic regression analysis of sources of variation in mating preferences of male and female $B$. treatae assayed from nochoice mating trials. This analysis evaluates the influence of the male and female B. treatae source population and the presence versus the absence of the host plant during mating trials on the probability of mating. Foliage $=$ present or absent; male and female host $=$ host plant species from which each sex was collected $(Q$. geminata or Q. virginiana).

\begin{tabular}{lccc}
\hline Source & df & $\begin{array}{c}\text { Likelihood } \\
\text { ratio } \chi^{2}\end{array}$ & $P$ \\
\hline Foliage & 1 & 1.76 & 0.1841 \\
Male host & 1 & 5.40 & 0.0202 \\
Female host & 1 & 0.06 & 0.7946 \\
Foliage $\times$ male host & 1 & 0.40 & 0.5256 \\
Foliage $\times$ female host & 1 & 1.87 & 0.1710 \\
Male host $\times$ female host & 1 & 60.76 & $<0.0001$ \\
Male host $\times$ female host $\times$ foliage & 1 & 6.48 & 0.0109 \\
\hline
\end{tabular}

be driven by variation of the male preference ( $t$-test: $t=$ 3.875 , df $=62, P<0.0003$; Figure $3(\mathrm{~A}))$ rather than the female preference ( $t$-test: $t=-0.49$, df $=63, P=0.9614$; Figure 3(B)).

\section{Discussion}

4.1. Host Preference, Mating Preference, and Population Differentiation. Spatially divergent selection among populations leading to local adaptation is recognized as being central to initiating the divergence of incipient species [41]. However, dispersal and gene flow among populations experiencing differing selective regimes is antagonistic to local adaptation, population differentiation, and speciation [42]. Habitat isolation arising from the evolution of habitat preferences can reduce dispersal between contrasting habitats and promote adaptive divergence $[8,10,33,36,43]$. Perhaps nowhere is this more evident than among herbivorous insect specialists, who tend to oviposit, feed, rest, develop, and mate on their host plants [23]. In the present study, we demonstrated that multiple populations of the gall former $B$. treatae, each inhabiting either of two closely related oak species $[37,38]$ each express strong preferences for their natal host plant species. This preference was especially apparent among females as shown in Figures 1 and 3. Our results are consistent with partial habitat isolation in gall wasps evolving as a byproduct of adaptation to different hosts, as has now been demonstrated in a number of plant-insect systems $[8,10,20]$. Our experimental assays of host preference demonstrated that (a) each host-associated population accepts its native oak more than the alternative sister species of oak, (b) populations vary in the degree of host preference exhibited, and (c) individuals within host-associated populations vary in the strength of their preference, a proxy for ecological specialization. In light of the spatial distribution of the two species of oaks throughout central Florida, our results suggest an active role for habitat isolation in the ongoing evolution of reproductive isolation in this species of gall former. Given that the expansive geographic range of $B$. treatae (Florida to Texas) spans the geographic ranges of the six species of closely related live oaks that constitute the series Virentes [37, 38, 40], our results hint at the as yet unexplored prospect of replicated regional differentiation in host preference within $B$. treatae. 
An underlying assumption of our current measurement of host preference is that time spent on a host plant is correlated with mating and oviposition decisions, as has been shown in other host-associated and ecologically divergent insect populations [44]. However, we consider residence time in our study to be a conservative measure of host preference, as in two other species that form host-associated populations, E. solidaginis and $R$. pomonella, the insect is more likely to sit on the alternate host plant than to mate or oviposit on it $[8,44]$.

Through mating assays we showed that individual $B$. treatae prefer to mate with individuals from their natal oak population rather than individuals from the alternative oak species. Most important to the present study was our explicit test of the role of host preference, an estimate of habitat isolation, on the degree of sexual isolation among these ecologically divergent host-associated populations. Here, comparing sexual isolation with and without host plants being present in the experimental arena does just this [10, 23]. We found that the presence of the host plant during mating trials increased the degree of sexual isolation among B. treatae reared from different host plants by reducing between-host matings by $47 \%$. Moreover, we found this effect to be associated with variation in the host plant preference exhibited by males as most matings occurred on the female's host plant, regardless of the type of cross (interpopulation or intrapopulation).

Our mating assays constituted "no-choice" conditions where females were paired with males from one of two possible populations. An alternative approach can involve "choice" experiments, in which individuals can choose between inhabitants from each population. "Choice" tests can offer a different perspective of mate choice, commonly observing stronger preferences than "no-choice" tests [45]. In our assays, we imagined the biologically relevant scenario to be one in which an individual on its native host plant encountered a single migrant in a "no-choice-" type scenario.

All adults assayed in both the host and mate preference trials were reared directly from their native host hence we cannot rule out host environment as a contributing factor to the observed patterns of host and mate preferences. Reciprocal transplant experiments, repeated across populations, will be needed to distinguish genetic and environmental contributions to the observed differences in habitat and mating preferences and assess the adaptive nature of these traits through measurements of the fitness of each population on the two host species. However, the observed differences in host preference, even if due to host environment, would still be expected to contribute to divergence of $B$. treatae populations, as parental generation migrant wasps would be predicted to be averse to settling on, or mating with individuals from, the alternative host plant. Thus, our experiments support a critical role for host plant use in promoting reproductive isolation among populations of $B$. treatae regardless of the underlying basis for preference variation. Future work will test additional populations in mate choice assays to assess the generality of the current support for the hypothesis that habitat isolation directly contributes to sexual isolation during mate choice.
4.2. Habitat Preference and Speciation. Divergent habitat (e.g., host plant) preferences can promote the speciation process in two ways: (a) directly by reducing encounters between potential mates and driving assortative mating and (b) indirectly by generally reducing gene flow, which facilitates overall adaptive divergence and increases the opportunity for postzygotic barriers to arise. Habitat preference is considered to act directly as a form of reproductive isolation; however, to date, only a modest number of studies have actually demonstrated that habitat preference results in assortative mating and reduced gene flow. Cage experiments show increased assortative mating between host-associated populations of Eurosta solidaginis gall flies when host plants are present relative to when they are absent [36]. Markrecapture studies of hawthorn and apple host races of Rhagoletis pomonella flies suggest that the tendency of flies to reproduce on the same host species used in earlier life cycle stages strongly reduces gene flow between the races $[8,10]$. Most convincingly, a combination of field and molecular data indicates that variation in host plant choice reduces gene flow between clover- and alfalfa-adapted populations of Acyrthosiphon pisum pea aphids [32].

Habitat preferences can also indirectly contribute to the speciation process by (a) reducing the constraining effects of gene flow on adaptive divergence in ecologically important traits $[13,33]$, (b) promoting postzygotic isolation through less fit hybrids [46-48], and (c) increasing the opportunity for Dobzhansky-Muller postzygotic barriers to arise [49]. Thus, when divergent habitat preference acts as a barrier to gene flow, additional prezygotic and postzygotic reproductive barriers can evolve via the byproduct model of ecological speciation $[1,10,23,50]$. Under this model, reproductive barriers evolve as an indirect consequence of reduced gene flow rather than as a direct result of selection.

4.3. Conclusions. While habitat isolation is thought to play a critical role in premating reproductive isolation among herbivorous insect populations and, in general, among all taxa undergoing ecological divergence and speciation, very rarely is the role of habitat selection directly tested [23]. In the present study, we used a combination of habitat preference and mate preference assays among ecologically divergent populations of the gall wasp Belonocnema treatae to document variation among populations in habitat (i.e., host plant) preference and examine the role of habitat isolation to overall reproductive isolation. Overall, all populations examined showed habitat fidelity and habitat preference decreased the probability of mating between individuals from alternative host plants. The increase in the degree of assortative mating due to the presence of the host plant during mate choice provides an example of the importance of habitat isolation in promoting reproductive isolation between hostplant-associated populations of herbivorous insects.

\section{Acknowledgments}

The authors thank M. Deyrup and Archbold Biological Station for providing laboratory space and help with host 
plant identification, J. L. Greene for help with experiments, and E. Silverfine for editorial comments.

\section{References}

[1] D. Schluter, The Ecology of Adaptive Radiation, Oxford University Press, Oxford, UK, 2000.

[2] D. Schluter, "Ecology and the origin of species," Trends in Ecology and Evolution, vol. 16, no. 7, pp. 372-380, 2001.

[3] H. D. Rundle and P. Nosil, "Ecological speciation," Ecology Letters, vol. 8, no. 3, pp. 336-352, 2005.

[4] E. Mayr, "Ecological factors in speciation," Evolution, vol. 1, pp. 263-288, 1947.

[5] T. Dobzhansky, Genetics and the Origin of Species, Columbia University Press, New York, NY, USA, 3rd edition, 1951.

[6] G. G. Simpson, The Major Features of Evolution, Columbia University Press, New York, NY, USA, 1953.

[7] D. J. Funk, P. Nosil, and W. J. Etges, "Ecological divergence exhibits consistently positive associations with reproductive isolation across disparate taxa," Proceedings of the National Academy of Sciences of the United States of America, vol. 103, no. 9, pp. 3209-3213, 2006.

[8] J. L. Feder, S. B. Opp, B. Wlazlo, K. Reynolds, W. Go, and S. Spisak, "Host fidelity is an effective premating barrier between sympatric races of the apple maggot fly," Proceedings of the National Academy of Sciences of the United States of America, vol. 91, no. 17, pp. 7990-7994, 1994.

[9] E. Rolán-Alvarez, K. Johannesson, and J. Erlandsson, “The maintenance of a cline in the marine snail Littorina saxatilis: the role of home site advantage and hybrid fitness," Evolution, vol. 51, no. 6, pp. 1838-1847, 1997.

[10] D. J. Funk, "Isolating a role for natural selection in speciation: host adaptation and sexual isolation in Neochlamisus bebbianae leaf beetles," Evolution, vol. 52, no. 6, pp. 1744-1759, 1998.

[11] H. D. Rundle, L. Nagel, J. W. Boughman, and D. Schluter, "Natural selection and parallel speciation in sympatric sticklebacks," Science, vol. 287, no. 5451, pp. 306-308, 2000.

[12] R. B. Langerhans, M. E. Gifford, and E. O. Joseph, "Ecological speciation in Gambusia fishes," Evolution, vol. 61, no. 9, pp. 2056-2074, 2007.

[13] P. Nosil, "Divergent host plant adaptation and reproductive isolation between ecotypes of Timema cristinae walking sticks," American Naturalist, vol. 169, no. 2, pp. 151-162, 2007.

[14] D. B. Lowry, R. C. Rockwood, and J. H. Willis, "Ecological reproductive isolation of coast and inland races of Mimulus guttatus," Evolution, vol. 62, no. 9, pp. 2196-2214, 2008.

[15] S. P. Egan, G. R. Hood, J. L. Feder, and J. R. Ott, "Divergent host plant use promotes reproductive isolation among cynipid gall wasp populations," Biology Letters, in press.

[16] J. A. Coyne and H. A. Orr, Speciation, Sinauer, Sunderland, Mass, USA, 2004.

[17] T. K. Wood and M. C. Keese, "Host-plant-induced assortative mating in Enchenopa treehoppers," Evolution, vol. 44, no. 3, pp. 619-628, 1990.

[18] L. Nagel and D. Schluter, "Body size, natural selection, and speciation in sticklebacks," Evolution, vol. 52, no. 1, pp. 209218, 1998.

[19] P. Nosil and B. J. Crespi, "Ecological divergence promotes the evolution of cryptic reproductive isolation," Proceedings of the Royal Society of London B, vol. 273, no. 1589, pp. 991-997, 2006.
[20] S. P. Egan and D. J. Funk, "Ecologically dependent postmating isolation between sympatric host forms of Neochlamisus bebbianae leaf beetles," Proceedings of the National Academy of Sciences of the United States of America, vol. 106, no. 46, pp. 19426-19431, 2009.

[21] C. S. Mcbride and M. C. Singer, "Field studies reveal strong postmating isolation between ecologically divergent butterfly populations," PLoS Biology, vol. 8, no. 10, Article ID e1000529, 2010.

[22] S. H. Berlocher and J. L. Feder, "Sympatric speciation in phytophagous insects: moving beyond controversy?" Annual Review of Entomology, vol. 47, pp. 773-815, 2002.

[23] D. J. Funk, K. E. Filchak, and J. L. Feder, "Herbivorous insects: model systems for the comparative study of speciation ecology," Genetica, vol. 116, no. 2-3, pp. 251-267, 2002.

[24] E. A. Bernays and R. F. Chapman, Host-Plant Selection by Phytophagous Insects, Chapman and Hall, London, UK, 1994.

[25] M. C. Singer and C. D. Thomas, "Evolutionary responses of a butterfly metapopulation to human- and climate-caused environmental variation," American Naturalist, vol. 148, pp. S9-S39, 1996.

[26] S. P. Carroll, H. Dingle, and S. P. Klassen, "Genetic differentiation of fitness-associated traits among rapidly evolving populations of the soapberry bug," Evolution, vol. 51, no. 4, pp. 1182-1188, 1997.

[27] C. Mitter, B. Farrell, and B. Wiegmann, "The phylogenetic study of adaptive zones: has phytophagy promoted insect diversification?" American Naturalist, vol. 132, no. 1, pp. 107128, 1988.

[28] B. D. Farrell, “'Inordinate fondness' explained: why are there so many beetles?" Science, vol. 281, no. 5376, pp. 555-559, 1998.

[29] B. D. Walsh, "On phytophagic varieties and phytophagic species," Proceedings of the Entomological Society of Philadelphia, vol. 3, pp. 403-430, 1864.

[30] G. L. Bush, "Sympatric host race formation and speciation in frugivorous flies of genus Rhagoletis (Diptera, Tephritidae)," Evolution, vol. 23, pp. 237-251, 1969.

[31] T. P. Craig, J. D. Horner, and J. K. Itami, "Hybridization studies on the host races of Eurosta solidaginis: implications for sympatric speciation," Evolution, vol. 51, no. 5, pp. 1552-1560, 1997.

[32] S. Via, "Reproductive isolation between sympatric races of pea aphids. I. Gene flow restriction and habitat choice," Evolution, vol. 53, no. 5, pp. 1446-1457, 1999.

[33] P. Nosil, C. P. Sandoval, and B. J. Crespi, “The evolution of host preference in allopatric vs. parapatric populations of Timema cristinae walking-sticks," Journal of Evolutionary Biology, vol. 19, no. 3, pp. 929-942, 2006.

[34] H. Katakura, M. Shioi, and Y. Kira, "Reproductive isolation by host specificity in a pair of phytophagous ladybird beetles," Evolution, vol. 43, no. 5, pp. 1045-1053, 1989.

[35] C. Linn Jr., J. L. Feder, S. Nojima, H. R. Dambroski, S. H. Berlocher, and W. Roelofs, "Fruit odor discrimination and sympatric host race formation in Rhagoletis," Proceedings of the National Academy of Sciences of the United States of America, vol. 100, no. 20, pp. 11490-11493, 2003.

[36] T. P. Craig, J. K. Itami, W. G. Abrahamson, and J. D. Horner, "Behavioral evidence for host-race formation in Eurosta solidaginis," Evolution, vol. 47, no. 6, pp. 1696-1710, 1993.

[37] J. Cavender-Bares, K. Kitajima, and F. A. Bazzaz, "Multiple trait associations in relation to habitat differentiation among 17 Floridian oak species," Ecological Monographs, vol. 74, no. 4, pp. 635-662, 2004. 
[38] J. Cavender-Bares and A. Pahlich, "Molecular, morphological, and ecological niche differentiation of sympatric sister oak species, Quercus virginiana and Q. geminata (Fagaceae)," American Journal of Botany, vol. 96, no. 9, pp. 1690-1702, 2009.

[39] J. N. Lund, J. R. Ott, and R. J. Lyon, "Heterogony in Belonocnema treatae Mayr (Hymenoptera: Cynipidae)," Proceedings of the Entomological Society of Washington, vol. 100, no. 4, pp. 755-763, 1998.

[40] J. Cavender-Bares, A. Gonzalez-Rodriguez, A. Pahlich, K. Koehler, and N. Deacon, "Phylogeography and climatic niche evolution in live oaks (Quercus series Virentes) from the tropics to the temperate zone," Journal of Biogeography, vol. 38, no. 5, pp. 962-981, 2011.

[41] T. J. Kawecki and D. Ebert, "Conceptual issues in local adaptation,” Ecology Letters, vol. 7, no. 12, pp. 1225-1241, 2004.

[42] P. Edelaar, A. M. Siepielski, and J. Clobert, "Matching habitat choice causes directed gene flow: a neglected dimension in evolution and ecology," Evolution, vol. 62, no. 10, pp. 24622472, 2008.

[43] D. I. Bolnick, L. K. Snowberg, C. Patenia, W. E. Stutz, T. Ingram, and O. L. Lau, "Phenotype-dependent native habitat preference facilitates divergence between parapatric lake and stream stickleback," Evolution, vol. 63, no. 8, pp. 2004-2016, 2009.

[44] W. G. Abrahamson and A. E. Weis, Evolutionary Ecology across Three Trophic Levels: Goldenrods, Gallmakers, and Natural Enemies, Monographs in Population Biology, Princeton University Press, Princeton, NJ, USA, 1997.

[45] J. A. Coyne, S. Elwyn, and E. Rolán-Alvarez, "Impact of experimental design on Drosophila sexual isolation studies: direct effects and comparison to field hybridization data," Evolution, vol. 59, no. 12, pp. 2588-2601, 2005.

[46] C. E. Linn Jr., H. R. Dambroski, J. L. Feder, S. H. Berlocher, S. Nojima, and W. L. Roelofs, "Postzygotic isolating factor in sympatric speciation in Rhagoletis flies: reduced response of hybrids to parental host-fruit odors," Proceedings of the National Academy of Sciences of the United States of America, vol. 101, no. 51, pp. 17753-17758, 2004.

[47] H. R. Dambroski, C. Linn, S. H. Berlocher, A. A. Forbes, W. Roelofs, and J. L. Feder, "The genetic basis for fruit odor discrimination in Rhagoletis flies and its significance for sympatric host shifts," Evolution, vol. 59, no. 9, pp. 1953-1964, 2005.

[48] J. L. Feder, S. P. Egan, and A. A. Forbes, "Ecological adaptation and speciation: the evolutionary significance of habitat avoidance as a postzygotic reproductive barrier to gene flow," International Journal of Ecology. In press.

[49] H. A. Orr and D. C. Presgraves, "Speciation by postzygotic isolation: forces, genes and molecules," BioEssays, vol. 22, no. 12, pp. 1085-1094, 2000.

[50] P. Nosil, B. J. Crespi, and C. P. Sandoval, "Host-plant adaptation drives the parallel evolution of reproductive isolation," Nature, vol. 417, no. 6887, pp. 440-443, 2002. 

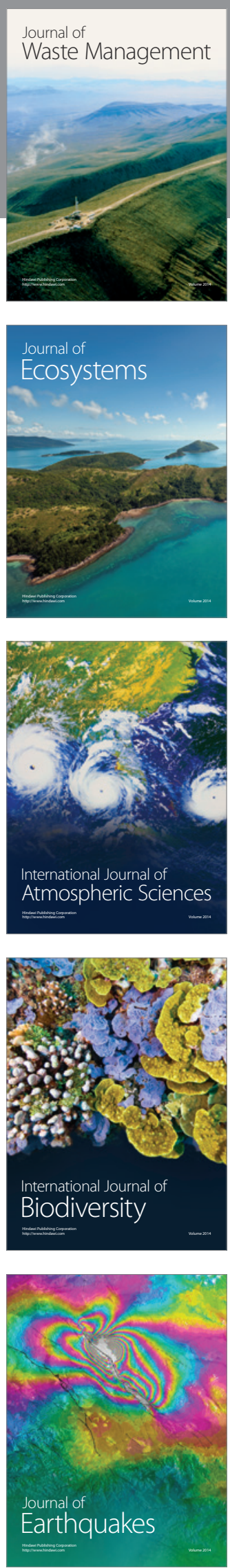
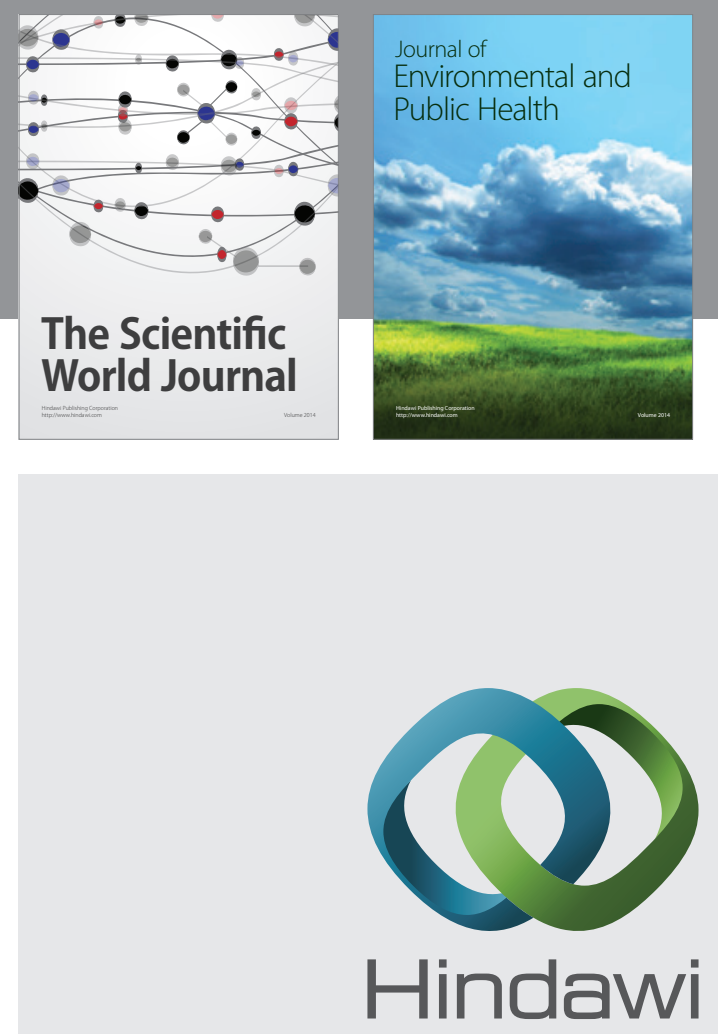

Submit your manuscripts at

http://www.hindawi.com
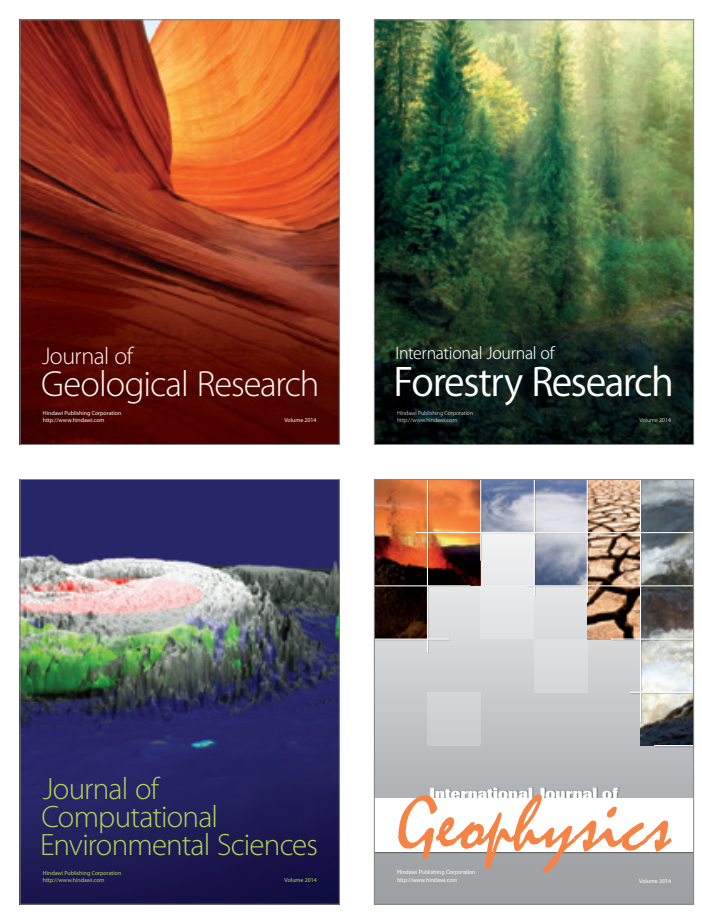
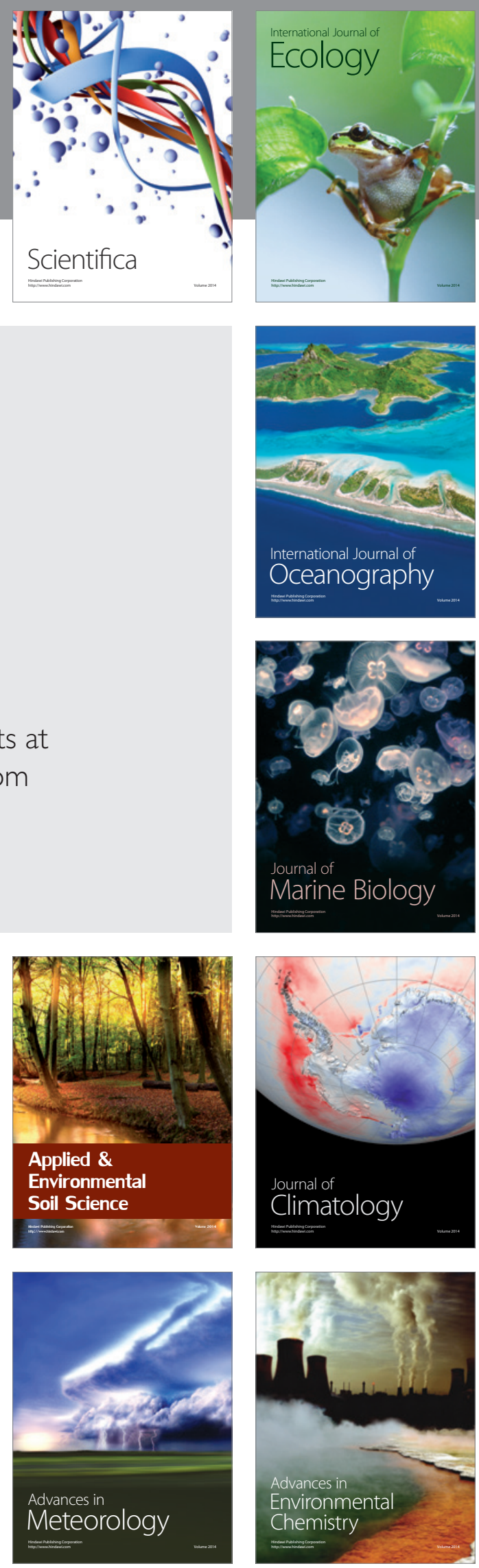